\title{
REDES SOCIAIS E DEMOCRACIA DELIBERATIVA
}

\section{SOCIAL NETWORKS AND DELIBERATIVE DEMOCRACY}

\author{
${ }^{1}$ Lucas Nogueira Garcez
}

\section{RESUMO}

Este artigo pretende conectar aspectos gerais das teorias deliberativas de democracia a mecanismos específicos disponíveis aos usuários das redes sociais. Aponta-se quais ferramentas das redes sociais colaboram com a constituição de uma esfera pública e o desenvolvimento de uma democracia deliberativa, especialmente quando incorporadas pela comunicação do Estado. Para tanto, reconstruímos sistematicamente a estrutura teórica da democracia deliberativa e, em seguida, avaliamos ferramentas específicas, ilustrando-as com exemplos nacionais de seu uso. Julgamos que esse tipo de análise é relevante para que se determine no futuro como estruturar a comunicação entre órgãos estatais e sociedade, de maneira a maximizar seu potencial deliberativo.

Palavras-chave: Democracia deliberativa, Esfera pública, Redes sociais, Ação performática, Controle

\begin{abstract}
This paper intends to connect general aspects of deliberative democracy theories to specific mechanisms available to social network users. We demonstrate which social network tools foster the constitution of a public sphere and the development of a deliberative democracy, specially when adopted by government communicative. To do so, we systematize the theoretical structure of deliberative democracy and evaluate specific tools, showing brazillian examples of its use. We believe this type of analysis is relevant to the conception of future communication between government agencies and society to maximize its deliberative potencial.
\end{abstract}

Keywords: Deliberative democracy, Public sphere, Social networks, Performative action, Control

1Mestrando em Direito e Desenvolvimento pela Fundação Getúlio Vargas - FGV, São Paulo, Brasil. E-mail: lucas.garcez@gvmail.br 


\section{INTRODUÇÃO}

O presente artigo busca conectar as propostas de legitimação das decisões do Estado fornecidas pelas teorias deliberativas da democracia com um mecanismo digital específico de comunicação: O uso de páginas nas redes sociais e a incorporação de certas ferramentas delas em suas páginas institucionais. Buscaremos mostrar que em grande medida essas ferramentas digitais proporcionam melhores condições de concretização das prescrições das teorias deliberativas, ainda que permaneçam alguns desafios a ser superados. Para tanto, esboçaremos, em primeiro lugar, o problema contemporâneo da legitimidade na democracia e no Direito. Em seguida apontaremos algumas linhas gerais comuns às correntes deliberativas de teoria da democracia. Demonstraremos a importância e as características da esfera pública, da sociedade civil e do debate para democracias deliberativas. Apontaremos, ainda, que as teorias contemporâneas da democracia deliberativa não ignoram nem os problemas da complexidade nem os limites da racionalidade: elas defendem a legitimação informal num debate que comporta tanto ações comunicativas quanto ações performáticas. Vale destacar que, não é objetivo deste trabalho explorar todas as características específicas de um modelo específico de democracia deliberativa. Nosso esforço se resume a traçar um quadro geral, um "framework" básico para avaliar o potencial deliberativo das ferramentas digitais de comunicação mencionadas. Por fim, apontaremos, observando alguns exemplos nacionais, quais elementos específicos de páginas governamentais em redes sociais e fora delas favorecem um desenvolvimento da democracia deliberativa, concluiremos com considerações sobre os limites e desafios ainda a ser enfrentados.

\section{LEGITIMIDADE E DEMOCRACIA}

Um dos debates mais relevantes para teoria política ao longo de sua história se deu em torno da questão da legitimidade das ações do Estado. De onde o Estado deriva a legitimidade para a produção de suas normas? Uma das principais respostas para essa pergunta foi a "autonomia", ou seja, a edição das normas pelos mesmos indivíduos que por elas seriam vinculados. Nessa visão, apenas a vontade do povo seria, portanto, capaz de conferir legitimidade ao poder legislativo do Estado (KANT, 2002, PP. 251 - 252). Ocorre que, ainda que se assuma possível falar em uma "vontade", há uma distância entre ela e as instituições do Estado. Dessa forma, a resposta da autonomia se mostra insuficiente sem que ela trate 
objetivamente da questão de superar a distância entre os indivíduos e o processo decisório no Estado.

Por muito tempo argumentou-se que a representação seria suficientemente apta a fazer tal tradução. O sistema eleitoral proporcionaria nas democracias o vínculo necessário para apreensão da vontade do representado pelo representante. Mesmo as teorias econômicas da democracia (DOWNS, 1999, p. 135) argumentam que os representantes, ainda que racionais e auto-centrados - voltados para a maximização do próprio bem-estar - podem agir de acordo com a ideologia dos representados, quando a estrutura do processo eleitoral nos regimes democráticos transforma a apreensão das ideologias no único meio que os representantes teriam para atingir a finalidade de maximizar seus votos.

Ocorre que ao longo do tempo as estruturas eleitorais convencionais se mostraram insuficientes para conferir legitimidade. Anthony Giddens (2005, p. 81) conecta, de maneira muito perspicaz, essa conclusão teórica com surveys realizados nos EUA, que apontaram que, embora a população demonstre cada vez menos confiança na classe política, uma parcela de 90\% dela ainda se dizia favorável a formas democráticas de governo. De fato, essa ambigüidade se nota também no Brasil, que embora tenha marcado sua opção pela transição para a democracia com a constituição de 1988, ainda apresenta baixos índices de confiança nas instituições do Estado e nos representantes eleitos. Surveys realizados em 2002, mais de 10 anos depois do advento da nova constituição, apontaram que $75 \%$ dos brasileiros não confiavam ou confiavam pouco nas Polícias Militares e 93\% não confiavam ou confiavam pouco nos partidos políticos (ALMEIDA, 2007, p. 189).

Podemos destacar duas estratégias principais concebidas pela literatura no intuito de ir além dos conceitos tradicionais de participação política e resolver os dilemas contemporâneos da legitimidade. A primeira consiste em conceber desenhos institucionais de participação direta de grupos da sociedade civil no processo decisório das instituições do Estado (AVRITZER, 2008, pp. 45 - 47). A segunda consiste em criar espaços de deliberação pública que contextualizem o processo decisório, criando envolvimento e accountability informal das decisões (SILVA e VIEIRA, 2013, pp. 154 - 155). Trataremos da segunda estratégia, largamente discutida pelas correntes deliberativas da teoria da democracia. Tais correntes ganharam força na onda de reflexões sobre a suficiência dos mecanismos tradicionais de participação democrática iniciada nos anos 90, chamada pela de virada deliberativa. 
Como demonstraremos a seguir, em linhas gerais, tais correntes apostam na superação da compreensão da participação como interferência formal no processo decisório. Acreditam que a participação consiste numa série de atos públicos e não apenas no ato privado do voto (SILVA, 2004, p. 2).

\section{TEORIAS DELIBERATIVAS DA DEMOCRACIA}

\section{A. Contexto}

A proposta deliberativa surge no contexto do debate entre liberais e republicanos como uma tentativa síntese. Tentou-se também enfrentar o diagnóstico da preponderância de concepções negativas da liberdade, em detrimento das positivas (BERLIN, 1981, pp. 133 - 175). Buscouse, assim, superar a dicotomia entre os modelos de democracia vigentes à época.

A concepção liberal, largamente associada à idéia de liberdade negativa, dá demasiada ênfase à circunscrição de um espaço de direitos básicos, sobre o qual não se poderia haver intervenção, assume a separação entre sociedade e Estado, e assume, ainda, a democracia como sistema para conduzir a ação do Estado na direção dos fins coletivamente visados. O cidadão, nesse caso, se define pela sua esfera de direitos subjetivos, proteções diante da ação do Estado, que garantem a ele a possibilidade de buscarem seus interesses privados.

Já na visão republicana a democracia não é meramente mediadora, ela é constitutiva da formação de sociedade. Sociedade e Estado estão unidos e a democracia caracteriza a própria liberdade de seus membros. O cidadão se define pela possibilidade de participação e não pela proteção diante do Estado (HABERMAS, 1995, pp. 39 - 41). A concepção republicana coloca, portanto, uma ênfase excessiva na coletividade e supervaloriza a possibilidade de construção do consenso.

As correntes de inspiração deliberativa se apresentam como uma síntese, pois ainda que considerem imprescindível a ação coletiva e a deliberação reconhecem como condição fundamental da existência da esfera pública a proteção de certos direitos, como igualdade e liberdade de expressão, imprescindíveis, inclusive, ao próprio processo deliberativo. Mantémse a separação liberal entre indivíduos e Estado, mas se reconhece na sociedade civil por eles 
constituída o espaço coletivo de construção da legitimidade das ações do Estado (ANDREWS, 2011, p. 123).

Num contexto de déficit de legitimidade, a política parece se exaurir em mudanças incrementais pouco significativas para a população. Assim, as teorias da democracia deliberativa reúnem ideais de responsividade com um grau alto de engajamento, reflexão e troca de ideias em debates públicos (SUSTEIN, 2000, p.73), vendo na esfera pública a única possibilidade de ampliação das transformações e da legitimação democrática das decisões. O debate público e formação da opinião pública são as únicas maneiras de proporcionar engajamento (KULYNYCH, 1997, p. 320) e fornecer substrato para tomada legítima de decisões na administração pública, que deve traduzir e dialogar com as idéias formadas nesse contexto. Nesse sentido, a participação é discursiva, feita através da argumentação e de acordos entre diferentes grupos e orientações ideológicas (GÜNTHER, 2002, pp. 113 - 114), de forma que cidadãos e representantes procuram justificar suas posições de maneira que haja aceitação mútua (GUTMANN e THOMPSON, 2004, p. 6).

\section{B. Esfera Pública, Sociedade Civil e Debate}

Vimos que a solução proposta pela corrente deliberativa baseia-se largamente na definição dos conceitos de "esfera pública", "sociedade civil" e "debate". Logo, exploraremos alguns aspectos destes conceitos.

Em primeiro lugar, a esfera pública não é um espaço físico, mas sim um fenômeno sociológico. Ela é o processo que ocorre quando existe uma rede de informação e comunicação na qual a ação política, mais precisamente a ação comunicativa ocorre. Ela é o campo em que os atores promovem seus discursos.

A sociedade civil, por sua vez, é um dos elementos constitutivos da esfera pública. Ela é composta por associações, organizações, grupos, e movimentos sociais, formais ou não, organizados espontaneamente em torno de problemas sociais específicos que impactam as vidas dos indivíduos. É necessário atentar, no entanto, que esses grupos não são grupos de interesses particulares (COHEN, 1997, pp. 67 - 71). O discurso presente na esfera pública é o discurso prático. Segundo a lógica de tal discurso, é necessário convencer que a norma de conduta defendida funda-se num interesse comum, generalizável (FREEMAN, 2000, pp. 375 
- 376). A ação política através do discurso prático é uma ação comunicativa, e justamente por ter uma lógica de convencimento e generalidade, freia a colonização do Estado por outros subsistemas e interesses privados.

Finalmente, o debate se verifica na esfera pública quando aqueles que participam procuram, através de seus discursos, o entendimento mútuo, o convencimento de sua reivindicação de validade. O convencimento e o consenso, no entanto, não podem ser vistos como um fim (COHEN, 1997, pp. 67 - 71). O consenso é uma possibilidade que marca a forma pela qual o debate é conduzido. Mesmo que esse consenso nunca seja alcançado os argumentos são oferecidos da maneira necessária à busca de um consenso (AVRITZER, 2000, p. 18). O consenso como finalidade só se manifesta, portanto, na linguagem, ou seja, os discursos são orientados pela possibilidade do consenso. Como consequiência, para que o consenso figure como finalidade na linguagem, a situação ideal de discurso é aquela em que os participantes estão em situação de igualdade (COHEN, 1997, pp. 67 - 71). Presente a submissão de um participante pelo outro não há que se falar no consenso nem como pressuposto da linguagem, visto que não é necessário convencer alguém dominado, cuja vontade é irrelevante (ANDREWS, 2011, pp. $27-28$ ).

Assim, resta claro que uma constituição que imponha um sistema político com circulação no poder procedimentos eleitorais democráticos não implica a existência de uma democracia deliberativa (VITA, 2003, p. 112). Essa estrutura não garante a existência de uma esfera pública capaz de conferir legitimidade às decisões tomadas na esfera estatal. São necessárias outras condições de igualdade e abertura para que a esfera pública posse se constituir. No mesmo sentido, a produção do Direito por representantes eleitos não garante sua legitimidade. É necessário reconhecer o papel político do Direito e permitir que as decisões, por meio da esfera pública, possam ser socialmente controladas. Tal controle se dá por meio de desenhos institucionais que exijam dos tomadores de decisão justificativas de suas escolhas que possam ser debatidas perante a esfera pública (RODRIGUEZ, 2013, p. 149). Nessa acepção um dos papéis da teoria do Direito é identificar e eliminar espaços institucionais que permitam a tomada de decisão sem a apresentação pública de justificativas (RODRIGUEZ, 2013, p. 150). 


\section{Complexidade e Racionalidade}

É preciso destacar, por fim, que a teoria deliberativa não ignora a constatação da complexidade. É reconhecida a exigência contemporânea de conhecimentos específicos para se compreender a realidade e formular políticas públicas. A sociedade complexa tem altos níveis de interdependência entre economia e Estado e exige especialização e burocratização. As possibilidades de produção de impactos concretos através de ações políticas são cada vez mais limitadas nesse contexto (KULYNYCH, 1997, p. 317). Ironicamente, como aponta Habermas, é no momento em que a complexidade exige uma expansão das atividades do Estado, e conseqüente aumento de seu papel nas vidas privadas, que os indivíduos perdem interesse na política e que o conceito de liberdade negativa ganha centralidade, em detrimento da liberdade positiva - da participação cívica. A síntese proposta pela teoria deliberativa justamente tem como referência essas sociedades complexas, com grande interdependência econômica e alto grau de pluralismo cultural e social. Busca-se, justamente, através da política deliberativa, tornar possível a participação e a legitimidade democrática da decisão, mesmo num contexto plural e complexo. A esfera pública opera conectando a geração informal de opiniões e o processo eleitoral formal e institucionalizado (HABERMAS, 1995, pp. 45 - 48).

A teoria lida com a questão afirmando que mesmo diante de tal complexidade a esfera pública não perde importância, pois só ela é capaz de mobilizar contra-especialistas, garantindo a capacidade de crítica e contestação mesmo em cenários complexos, em que a tecnocratas tem papel central. Justamente por isso, desnaturaliza-se a associação entre participação e tomada de decisão na administração. Ao contrário do que se esperava no modelo Grego de participação, os membros da sociedade, engajados na esfera pública, não têm que tomar a decisão, mas sim supervisionar e influenciar o exercício do poder pela administração pública através de seus discursos, avaliando as justificativas apresentadas para tomada de decisão. A participação forma o contexto no qual o Estado decide e se fundamenta, mas não o substitui na tomada de decisão (COHEN e ARATO, 1992, 222). Ela figura como um instrumento de controle e de vinculação dos representantes, e não como uma forma de democracia direta. Ela deve promover discussões e trazer a tona temas que seriam decididos unilateralmente e sem justificativa pela administração. Nesse sentido, a participação essencial é a participação informal. A legitimidade das decisões do Estado vem do fato de suas justificativas estarem ancoradas no que foi produzido livremente no debate público. O problema não está na 
complexidade, mas sim na insuficiência dos modelos normativos tradicionais de democracia de lidarem com a questão (COHEN e ARATO, 1992, 222).

Assim, ainda que a complexidade torne inevitável a atuação da administração pública, sua atuação normativa deve observar formas de comunicação aptas a legitimar as normas produzidas. Ela deve ir além das obrigações de transparência e divulgação de informações, deve constituir espaços aptos a formar a esfera pública.

Vale destacar, ainda, que nas correntes deliberativas todas as normas de conduta são questões política. Nesse sentido a deliberação política não busca tornar a sociedade homogênea, consensual, incluindo indivíduos num padrão de comportamento, ou apenas conferir legitimidade às decisões futuras. Figura também como forma de desnaturalizar ideias, figura como forma de impedir a simples aceitação de práticas vigentes. Qualquer circunstância que escape à deliberação política não pode ser considerada como legitimada por julgamentos racionais (KYMLICKA, 2006, pp. 285 - 286).

Nesse sentido, vale destacar que autores como Jéssica Kulynych (1997) vão além de concepção puramente racional do debate na esfera pública, especialmente no caso de práticas e ideias naturalizadas. Observam, com larga inspiração Foucalutiana, que a sociedade atual não é só marcada pela complexidade, é marcada também pela presença de tecnologias disciplinares e mecanismos pouco visíveis de cristalização das relações de poder. Essas tecnologias não se baseiam na violência física, mas no controle de desejos, expectativas, linguagens etc. A existência de tais tecnologias implica que há regras implícitas de gênero, raça e classe naturalizadas e que justamente por isso dificilmente são acessadas pelo debate puramente racional na esfera pública. A desigualdade de gênero, por exemplo, é tão intrínseca à linguagem e está tão imbricada com processo de socialização que a própria comunicação parte de uma "herança simbólica". Essa herança impede, por exemplo, que a mulher seja reconhecida como um interlocutor igual ao homem no debate, o que inviabiliza todo o desenvolvimento do debate público racional (KULYNYCH, 1997, pp. 324 - 326). Um dos pressupostos da esfera pública é a igualdade, e apenas pelo debate racional não é possível construí-la. A imposição da racionalidade excluiria discursos que evocassem cultura, emoções, humor e ironia, que são centrais no debate contemporâneo, sobretudo para desconstruir as "heranças simbólicas" naturalizadas, nem sempre acessíveis no debate racional. Nesse sentido Kulynych (1997, pp. 333 - 334) sugere outra dimensão da participação na esfera pública, que 
é a ação performativa, que problematiza as heranças simbólicas de maneira teatral, tirando a deliberação do confinamento da racionalidade imposta pela teoria deliberativa tradicional. Ainda que em última análise todas as normas de conduta possam ser analisadas do ponto de vista racional, apreensão racional de certos temas não pode ser feita sem que antes sejam problematizados de maneira performática.

Encerramos o tópico destacando que as teorias deliberativas iniciaram uma onda de revisão teórica sobre o conceito de participação e oferecem um referencial teórico interessante, que será adotado na presente análise das transformações políticas que a internet tem tornado possível. Seguiremos identificando como a presença de órgãos do Estado nas redes sociais, ou a adoção de certas funções típicas de redes sociais em suas páginas, se conecta com a idéia de constituição de uma esfera pública, que ofereça à sociedade civil a possibilidade de travar um debate aberto a ações comunicativas e ações performáticas.

\section{REDES SOCIAIS E ESFERA PÚBLICA.}

\section{A. Uso de Redes Sociais pelo Estado: Histórico e Exemplos.}

Com a crescente importância das redes sociais os departamentos de comunicação das empresas se apressaram para usar essas redes como ferramentas para alcanças os potenciais consumidores. Esse uso possibilitou um crescimento ainda maior das redes, que passaram a cobrar por serviços de comunicação social prestados às empresas. Na esteira desse movimento também órgãos Estatais passaram a constituir páginas nas redes sociais e usá-las como instrumento de comunicação. No Brasil, o uso das redes sociais pelo Poder Executivo foi consolidado pelo decreto 7.565 de janeiro de 2012 (BRASIL, 2012) e pela portaria 38 de junho de 2012 (BRASIL, 2012). As duas normas reconheceram explicitamente a importância das redes sociais e a possibilidade de órgãos e entidades da administração pública direta e indireta formarem perfis institucionais nessas redes. Atribuiu-se ao Departamento de Governo Eletrônico a competência de definir os padrões de uso das redes sociais por tais órgãos e entidades. O Poder Executivo Federal entende por mídias sociais "sistemas online projetados para permitir a interação social a partir do compartilhamento e da criação colaborativa de informação nos mais diversos formatos" que "possibilitaram a publicação de conteúdos por qualquer pessoa, baixando a praticamente zero o custo de produção e distribuição ao longtail” (BRASIL, 2012). Os exemplos são Blogs, Wikipedia, Facebook, Second Life, Twitter, entre 
outros. A criação das páginas demonstrou grande sucesso. Temos como exemplo a página da Presidência da República no Facebook, que é atualmente seguida por mais de cento e vinte mil usuários, e as páginas do Ministério da Saúde e do Ministério da Educação que têm, por sua vez, mais de seiscentos mil usuários que as seguem ${ }^{1}$.

\section{B. Redes Sociais: Alguns Aspectos Estruturais.}

Como tudo no campo da internet, as redes sociais estão em constante transformação. As redes sociais mais influentes podem passar a ser obsoletas ao longo do tempo ou podem transformar suas ferramentas e seu formato. Dessa forma, a análise deste trabalho não se focará em nenhuma rede social específica, mas sim em determinadas ferramentas específicas, que podem estar presentes em mais de uma rede social ou até mesmo em uma página governamental fora de tais redes.

\section{Publicação Atualizada de Conteúdo:}

Característica quase geral de quase toda página governamental dentro e fora das redes sociais, a publicação atualizada de conteúdo implica publicação esporádica de novas informações na página, o que dá a ela um caráter dinâmico. O conteúdo presente na página varia com o tempo, e ela funciona como um mecanismo de divulgação de notícias ou acontecimentos recentes relativos ao órgão (BRASIL, 2012, p. 28).

\section{Ferramentas de Compartilhamento:}

Presentes em diversas páginas e redes sociais as ferramentas de compartilhamento possibilitam que o usuário que acessa o conteúdo publicado na página do órgão governamental possa remeter esse conteúdo a espaços próprios. Isso pode ser feito por meio de mensagens privadas, como e-mails, por exemplo, ou em um perfil público do usuário em

\footnotetext{
${ }^{1}$ As páginas desses órgãos no Facebook contém links para suas páginas oficiais e adotam um discurso mais aberto e próximo no Facebook, convidando os usuários a interagir com a administração, como se vê em: https://www.facebook.com/PalacioDoPlanalto/timeline <Acesso em Junho de 2014>, https://www.facebook.com/minsaude <Acesso em Junho de 2014> e https://www.facebook.com/ministeriodaeducacao <Acesso em Junho de 2014>.
} 
uma rede social. Quando o conteúdo é compartilhado, é aberto um novo espaço de debate acerca do conteúdo, que não se mistura com os espaços abertos por sua publicação inicial e que não é controlado pelo usuário que publicou o conteúdo inicial. Essa ferramenta está presente, por exemplo, no Facebook, que possibilita ao usuário compartilhar conteúdo encontrado dentro e fora da rede social em perfis públicos, mensagens ou grupos privados (FACEBOOK, 2014).

\section{Ferramentas de Comentários:}

Tão importantes quanto as ferramentas de compartilhamento, os comentários possibilitam que os usuários que acessam o conteúdo não apenas recebam informações, mas também enviem suas próprias percepções ou conteúdos, que passam a ficar anexados ao conteúdo publicado. Essas ferramentas de comentário possibilitam um espectro relativamente amplo de resposta ao conteúdo inicialmente postado, de forma que o usuário pode responder com texto, links, vídeos ou fotos. Os comentários aparecem instantaneamente na página em que o conteúdo inicial foi publicado, e podem ser acompanhados em tempo real por todos os usuários que acessam a página no momento que são publicados (FACEBOOK, 2014).

\section{Efeitos}

Discutiremos agora os possíveis efeitos positivos de páginas governamentais dentro e fora de redes sociais que possuam essas duas ferramentas típicas delas.

Em primeiro lugar, surge a seguinte questão: se o conteúdo básico das páginas é controlado por seus, administradores, funcionários do órgão titular da página (BRASIL, 2012, p. 38), o que há de inovador nesse mecanismo? Qual é a diferença entre a divulgação de informações escolhidas pelos órgãos públicos (e, portanto com um viés favorável a eles) no Diário Oficial ou em páginas das próprias instituições que não tenham as ferramentas descritas?

A existência das ferramentas, embora pareça uma diferença singela, é muito significativa. Isso porque ao divulgar qualquer informação, ainda que enviesada, o órgão se abre para o público e perde o controle do impacto que a divulgação terá em seus comentários. É possível que o debate conduzido nos comentários e nos compartilhamentos seja dirigido ao sentido 
oposto do desejado pelo divulgador. É por isso que a estrutura de divulgação de informações com possibilidade de comentários figura como um instrumento de constituição da esfera pública. Estão presentes diversos elementos listados na definição de esfera pública descrita. A informação originária divulgada pelo órgão dá uma direção temática do que será debatido nos comentários, conectando invariavelmente a decisão com a existência de um debate público sobre o tema. Ao tomar contato com a informação, a população passa a visualizar tal processo decisório. A abertura das redes sociais ainda possibilita tanto a ação comunicativa quanto a ação performática, já que no mesmo espaço que é possível deixar um argumento escrito é possível inserir fotos ou vídeos humorísticos. Ainda é possível que se siga uma discussão racional de reflexões provocadas pela inserção desse conteúdo performático. Outro aspecto a ser notado sobre essa estrutura é que ela é cada vez mais incorporada às expectativas e demandas coletivas, de forma que se tornou um padrão mínimo de abertura. Mesmo outras páginas na internet que não as redes sociais passaram a adotar essa estrutura. Inclusive, em recente media da Presidência da República, o Estado brasileiro passou a reconhecer, no Decreto $\mathrm{n}^{\circ} 8.243$ a necessidade - e não mais apenas a possibilidade - de todos os órgãos públicos contarem com "ambiente virtual de participação social - mecanismo de interação social que utiliza tecnologias de informação e de comunicação, em especial a internet, para promover o diálogo entre administração pública federal e sociedade civil" (BRASIL, 2014).

Vale destacar também que a abertura das páginas com tais ferramentas também possibilitam o encontro de indivíduos ideologicamente distintos, que talvez não se encontrassem em outros espaços. Essa característica se conecta com a literatura que aponta a necessidade de espaços de debates heterogêneos, com indivíduos muito variados do ponto de vista ideológico, como forma de prevenir a polarização das posições políticas e melhorar o caráter deliberativo da democracia (SUSTEIN, 2000, pp. 113 - 114).

Por fim, vale destacar que as redes sociais também oferecem uma alternativa às mídias tradicionais, que tem vivido, até o advento da internet, uma tendência de controle da informação e concentração de mercado (AVELAR e CINTRA, 2007, p. 406). A concentração também pode ocorrer nas empresas provedoras de internet, mas ao contrário do que ocorre nas mídias sociais, não há um impacto dessa concentração sobre o controle do conteúdo. Emissoras de rádio e TV não oferecem simplesmente um serviço de transmissão de dados. As informações que divulgam são por eles construídas e controladas, de forma que a concentração do mercado implica necessariamente uma restrição maior de conteúdo, criando 
certo grau de controle da política (AVELAR e CINTRA, 2007, p. 412). Ao contrário, as empresas provadoras de internet, graças à neutralidade de rede, recentemente garantida pelo art. $9^{\circ}$ Marco Civil da Internet (BRASIL, 2014), tornam possível a transmissão de dados sem qualquer controle de quais dados serão acessados através de seus serviços, de forma que a concentração de mercado ou influência das empresas só importa para o preço do serviço.

\section{DEMOCRACIA DIGITAL COMO OPERACIONALIZAÇÃO DA DEMOCRACIA DELIBERATIVA LIMITES E POSSIBILIDADES.}

Embora a abertura das informações divulgadas nas páginas de órgãos do Estado em redes sociais se aproxime em muitos pontos com a idéia de democracia deliberativa, facilitando o debate sobre determinados temas, aproximando os desdobramentos do debate da administração pública e possibilitando tanto a ação comunicativa quanto a ação performática há uma série de limites a ser considerados.

Em primeiro lugar, há um viés criado pela própria possibilidade de acesso à internet. Há um viés de raça, idade e, sobretudo, de classe no acesso à internet (HINDMAN, 2009, pp. 8 - 9) e às páginas dos órgãos públicos. Nem todos os cidadãos têm acesso à internet, nem todos conhecem as páginas governamentais e nem todos conseguem compreendê-las. O viés também pode ser destacado em termos de tempo, já que aqueles indivíduos que por quaisquer outros motivos tem restrições de tempo, tal como trabalhadores submetidos a maiores jornadas de trabalho e longo tempo de locomoção, participarão menos dos debates que os demais (FARIA, 2013, p. 89). Em segundo lugar, há a possibilidade de moderação enviesada dos comentários e conseqüente manipulação dos seus desdobramentos (HINDMAN, 2009, pp.

12 - 13). Em terceiro lugar, não há garantias de que o Estado vá incorporar qualquer dos desdobramentos do debate em sua decisão (HINDMAN, 2009, pp. 16 - 17). Em quarto lugar, há o problema da filtragem do conteúdo pelas redes sociais ou ferramentas de busca.

Apesar de válidas, essas críticas não podem ser superestimadas. A possibilidade de moderação dos comentários, por exemplo, é restrita por alguns fatores. Em primeiro lugar, os debates ocorrem não apenas nas páginas oficiais, mas também nos compartilhamentos das publicações. Na estrutura descrita das redes sociais o controle dos debates travados em cada compartilhamento é difícil. Além disso, ainda que o debate ocorra na publicação originária, quando ele ocorre em tempo real o número de comentários é grande demais para que haja um 
controle tão específico do conteúdo. Claro que seria possível usar programas que exercessem o controle, por exemplo, por palavras-chave. Nesse caso a dificuldade do controle seria social: os participantes do debate notariam que seus comentários teriam desaparecido e a informação sobre o controle seria divulgada em outras páginas, sobre as quais o Estado não tem controle ${ }^{2}$. O próprio executivo reconhece esse fato, de forma que a política adotada é de não excluir comentários críticos, mas sim lidar com eles. O próprio Estado assume que os comentários dificilmente são controlados e que a exclusão de um comentário pode provocar uma crise ainda maior, recomendando a moderação apenas quando há ofensas pessoais (BRASIL, 2012, pp. $11-12)$.

No que tange a garantia de incorporação dos desdobramentos dos comentários pelo Estado é preciso voltar à própria idéia de democracia deliberativa. A existência do debate garante que o Estado pode acessar o conteúdo, garante que os envolvidos saibam das questões nele levantadas e, por fim, que saibam que o Estado pôde acessar esse conteúdo. Dessa forma, caso a decisão seja tomada ignorando os argumentos levantados, os envolvidos verão com clareza o afastamento entre a decisão e o debate. Assim, a responsabilização do tomador de decisão fica facilitada, e os impactos do desvio são ampliados. O papel deliberativo é cumprido se presente a estrutura necessária para um debate na esfera pública.

Há duas críticas que, de fato, impactam com maior peso os potenciais das ferramentas sob análise. A primeira é a do viés. De fato, a internet impõe largo viés de acesso, que prejudica a realização do potencial da internet. Para que os espaços virtuais de comentários e debates sobre ações do Estado cumpram integralmente seu papel deliberativo o acesso à internet e o tempo disponível teriam de ser mais igualitários. Por outro lado, esse argumento não opõe necessariamente o uso das redes sociais, mas pode, pelo contrário, justificar a ampliação não só de seu uso, mas também de seu acesso. Além disso, ainda que no Brasil não seja toda a população que acessa a internet, o número de usuários é significativo: em torno de 80 milhões dos quais 90,8\% acessam redes sociais (BRASIL, 2012, pp. 11 - 12). Por fim, vale destacar que no curto prazo, antes de qualquer ampliação do acesso, a internet ainda pode impactar a formação de opinião, mesmo de quem não a acessa. Isso se dá uma vez que questões

\footnotetext{
${ }^{2}$ Um exemplo disso foram as críticas feitas a candidatos à Presidência da República no Brasil em suas páginas. Ainda que o controle fosse exercido, através da exclusão dos comentários, a ação foi percebida e divulgada em outras páginas, provadas com capturas de tela. O mesmo ocorre com páginas de notícias que tentam fazer um controle ideológico dos comentários realizados. Mesmo quando o controle é exercido pela própria rede social ele é percebido e divulgado:

http://oglobo.globo.com/brasil/facebook-admite-que-apagou-post-de-dilma-bolada-sobre-aecio-neves-8539996
} 
suscitadas nos debates nela ocorridos chegam a essas pessoas pela via indireta, quando têm contato com outras que participaram diretamente do debate (BRASIL, 2012, p. 8).

A segunda crítica significativa é a relativa aos filtros. A informação disponível na internet é muito maior do que a capacidade de absorção do usuário. Assim, redes sociais e ferramentas de busca criaram algoritmos que selecionam algumas informações e as privilegiam, colocando-as em destaque para o usuário. Esses algoritmos podem ter diversos critérios. Alguns usam o próprio histórico de uso dos indivíduos para criar seus filtros. Esse uso, no entanto, coloca o usuário numa bolha, de forma que uma vez acessados determinados conteúdos, as páginas só mostraram a ele conteúdos semelhantes. A rede social usada como exemplo diversas vezes nesse artigo, o Facebook, possuí seus filtros que selecionam quais publicações vão aparecer em primeiro lugar quando o usuário acessa a rede. Assim, além do usuário estar restrito à divulgação de informações feitas pelas páginas que segue ou dos demais usuários por ele adicionados, a ordem de aparição das publicações desses usuários e páginas em sua tela é determinada por diversos filtros, como, por exemplo, o tempo de interação com cada usuário (PARISER, 2008, pp. 38 - 42). Assim, é possível identificar em tais filtros uma restrição ao potencial deliberativo das publicações dos órgãos governamentais. Os indivíduos podem ficar restritos a informações semelhantes às que buscam usualmente, sem acessar outros debates. Por outro lado, há dois fatores que atenuam esses efeitos. Em primeiro lugar, é preciso lembrar que esses filtros se aplicam às publicações que aparecem na página inicial da rede, mas não aos comentários em tempo real feitos em publicações ou compartilhamentos. Em segundo lugar, a possibilidade de seguir as páginas governamentais funciona como um mecanismo de "bypass" dos filtros, que operariam com maior peso se o usuário apenas pudesse tomar contato com o conteúdo quando do compartilhamento por outro usuário.

\section{CONSIDERAÇÕES FINAIS.}

Vimos algumas situações em que a internet tem grande potencial na concretização de prescrições das teorias deliberativas da democracia e também desafios a ser superados. São necessários mais estudos sobre esses potenciais e dificuldades práticas para que desenhe as formas mais inclusivas de uso democrático das redes. 


\section{REFERÊNCIAS}

ALMEIDA, Alberto Carlos. A Cabeça do Brasileiro. Rio de Janeiro: Record, 2007.

ANDREWS, Christina W. Emancipação e Legitimidade: Uma introdução à obra de Jurgen Habermas. São Paulo: Editora Unifesp, 2011.

AVELAR, Lucia; CINTRA, Antônio O. Sistema Político Brasileiro: Uma introdução. Editora Unesp. São Paulo. 2007.

AVRITZER. Leonardo. Instituições participativas e desenho institucional: algumas considerações sobre a variação da participação no Brasil democrático. in Opinião Pública, Campinas, vol. 14, n 1, Junho, 2008, p.45-47.

AVRITZER, Leonardo. Teoria democrática e deliberação pública. Lua Nova, São Paulo, n. 50, 2000 . Disponível em <http://www.scielo.br/scielo.php?script=sci_arttext\&pid=S010264452000000200003\&lng=pt\&nrm=iso>. (acesso em junho de 2014).

BERLIN, Isaiah. Dois Conceitos de Liberdade. in Quatro Ensaios sobre a Liberdade. Brasília: Editora UNB. 198.

BRASIL, Conselho de Defesa Nacional. Portaria $\mathbf{n}^{\mathbf{0}}$ 38/2012. Disponível em: http://www.governoeletronico.gov.br/biblioteca/arquivos/portaria-no-38-de-11-6-2012homologa-a-norma-complementar-no-15-in01-dsic-gsipr-sobre-o-uso-das-redes-sociais-naadministracao-publica-federal/view <Acesso em Junho de 2014>.

BRASIL, Presidência da República, Lei 12.965/14, 2014. Disponível em: http://www.planalto.gov.br/ccivil_03/_ato2011-2014/2014/lei/112965.htm <Acesso em Julho de 2015>

BRASIL, Presidência da República, Casa Civil, Decreto $\mathbf{n}^{\mathbf{0}} \mathbf{7 6 7 5 / 2 0 1 2}$, disponível em http://www.governoeletronico.gov.br/biblioteca/arquivos/decreto-no-7-675-de-20-de-janeirode-2012/download <Acesso em Junho de 2014>.

BRASIL, Presidência da República, Casa Civil, Decreto 8.243/14, 2014, disponível em: http://www.planalto.gov.br/ccivil_03/_Ato2011-2014/2014/Decreto/D8243.htm <Acesso em julho de 2015>.

BRASIL, Secretaria de Comunicação Social da Presidência da República. Manual de Orientação Para Atuação em Redes Sociais. 2012. Disponível em http://secom.gov.br/pdfsda-area-de-orientacoes-gerais/internet-e-redessociais/secommanualredessociaisout2012_pdf.pdf <Acesso em Junho de 2014>.

COHEN, Jean. L. e ARATO, Andrew. Civil Society and Political Theory. MIT Press. New Baskerville. 1992

COHEN, Joshua. Deliberation and Democratic Legitimacy in BOHMAN, James. REHG, William. Deliberative Democracy: Essays on Reason and Politics. Cambridge. MIT Press. 1997. 
DOWNS, Anthony. Uma teoria econômica da democracia. São Paulo: EdUSP, 1999.

FACEBOOK, Ajuda Para Desktop: Compartilhamento. https://www.facebook.com/help/368307356561545/ <Acesso em Junho de 2014>.

FACEBOOK. Para Ajuda Desktop: Comentários. https://www.facebook.com/help/499181503442334/ <Acesso em Junho de 2014>.

FARIA, Cristiano F. S. The Open Parliament in the Age of the Internet: Can the people now collaborate with legislators in lawmaking. Edições Câmara. Brasília. 2013.

FREEMAN, Samuel. Deliberative Democracy: A Sympathetic Comment. Philosophy and Public Affairs. V. 4. 2000.

GIDDENS, Anthony. A Terceira Via: Reflexões sobre o impasse político atual e o futuro da social democracia. Rio de Janeiro: Record, 2005.

GÜNTHER, Klaus. Responsabilização na Sociedade Civil. in Revista Novos Estudos CEBRAP. São Paulo, n. 63, 2002.

GUTMANN, Amy; THOMPSON, Dennis. Whey Deliberative Democracy? Princeton : Princeton University Press. 2004.

HABERMAS, Jürgen. Três Modelos Normativos de Democracia. in . Lua Nova, São Paulo , n. 36,1995 . pp. $39-41$.

HINDMAN, Matthew. The Myth of Digital Democracy. Princeton University Press, Princeton. 2009

KANT, Immanuel. A Filosofia do Direito. in MORRIS, Clarence. (org.) Os Grandes Filósofos do Direito. São Paulo: Martins Fontes. 2002.

KYMLICKA, Will. Filosofia Política Contemporânea. Martins Fontes. São Paulo. 2006.

KULYNYCH, Jéssica J. Performing Politics: Focault, Habermas and Postmodern Participation. in Polity, Boston, v. 30, n. 2. 1997.

PARISER, Eli. The Filter Bubble: What the internet is hiding from you. The Penguin Press. New York. 2008.

RODRIGUEZ, José Rodrigo. Como decidem as cortes? Para um crítica do Direito Brasileiro. Rio de Janeiro: Editora FGV, 2013.

SILVA, Filipe C. e VIEIRA, Mônica B. Democracia Deliberativa Hoje: Desafios e perspectivas. Revista Brasileira de Ciência Política, n. 10. Brasília, 2013, pp. 154 - 155 
SILVA, Filipe C. Democracia deliberativa: Avaliando os seus limites. II Congresso da Associação Portuguesa de Ciência Política. Fundação Calouste Gulbenkian: 2004. p. 2. <disponível em http://www.ces.fe.uc.pt/publicacoes/oficina/203/203.pdf, acesso em junho de 2014>

SUSTEIN, Cass R. Deliberative Trouble? Why Groups Go to Extremes. in The Yale Law Journal. New Haven. V. 110. 2000.

VITA, Álvaro. Democracia deliberativa ou igualdade eqüitativa de oportunidades? in Novos Estudos CEBRAP,v. 66, 2003. 